\title{
The Survey of Factors Influencing Sustainable Tourism at Patong Beach, Phuket Island, Thailand
}

\author{
Maythawin Polnyotee \\ PhD candidate (Interdisciplinary in Environment, Development and Sustainability), \\ Graduate School, Chulalongkorn University, Bangkok, Thailand \\ Email address: maythawin.hos.msu@gmail.com
}

Associate Professor Suwattana Thadaniti (Ph.D)

Advisor, Chulalongkorn University Social Research Institute, Chulalongkorn University, Bangkok, Thailand Doi:10.5901/mjss.2014.v5n9p650

Email address: tsuwattana@yahoo.com

\section{Abstract}

This paper presents a study of the existing tourism situation at Patong Beach and the factors influencing sustainable tourism at Patong Beach. The objectives of this study are to analyze the existing tourism situation and explore the factors influencing sustainable tourism at Patong Beach using direct observation and questionnaire. One hundred twenty local people were asked their perspectives concerning impacts of tourism and people participation. Meanwhile, 120 tourists were interviewed on tourist attraction, accessibility, facility, and security/safety. According to data collection by observation, we found that the existing tourism situation is faced with problems, particularly, environmental, economical, and social. At the same time, the questionnaire data analyzed using the Likert scale found that local people agreed that tourism caused a high impact $(\bar{x}=3.87)$ and people participation was moderate $(\bar{x}=2.82)$, whereas data from tourist attitude showed that tourist attraction is highly competent $(\bar{x}=3.59)$, and accessibility $(\bar{x}=3.14)$, facility $(\bar{x}=3.07)$, and security/safety $(\bar{x}=3.10)$ are moderate. In conclusion, Patong Beach has high tourism competency but there are many factors influencing sustainable tourism as shown in the existing tourism situation (i.e., high impact of tourism). On the other hand, people participation is low. Finally, Patong Beach should be developed in the way of sustainable tourism development, people participation, and community-based tourism all together.

Keywords: Sustainable Tourism Development, Community-based Tourism, People Participation

\section{Introduction}

Phuket is a well-known world class tourism destination because of the varieties of attraction and awards garnered, such as Best Asian Maritime Capital (Thaimuslinnews, 2011), Kinnaree Awards (ASTV,2011), City: Best Leisure Destination in Asia-Pacific (ASTV,2011), $6^{\text {th }}$ Favorite destination for Chinese tourist, Winter Destination for Finnish Tourist, $5^{\text {th }}$ place of Best Island in Asia World's Best Award 2010 (Travel and Leisure Magazine, 2010), $8^{\text {th }}$ place of 'Reader's Travel Award 2009: Island (Conde' Nest Traveler Magazine, 2010), and 29th Top City Destination in 2009 by Euromonitor International (2012).

The place where all tourists, whether Thai or foreigner, truly visit when going to Phuket is Patong Beach or Patong City. The tourist can be impressed with the wide and long beautiful beach with a stone hill at the end of two sides of the beach that extends to the sea approximately 200-300 meters. Moreover, the feature of shallow wave in all seasons with 30-40 meter-distance from the coast allows tourists to enjoy swimming year-round. Patong Beach is attractive for relaxing, swimming, water recreation, and water activities, including special events such as Songkran on the beach, Patong Carnival, Phuket Bike Week, diving, Hay Island, Racha Yai, and fishing. In terms of accessibility, Patong Beach is located far from Phuket, approximately 15 kilometers downtown. Tourists can access Patong Beach by using various vehicles such as public car, charter car, private car, motorcycle, or even bicycle.

In terms of tourist motivation, the research conducted by Jittima Kaewtae (Jittima, 2005), which is "Acceptance of news, Expectation and satisfaction of Thai tourists toward Patong beach, Phuket province" found that the main reason for visiting Patong Beach was its attractive environment. On the other hand, the research conducted by Panisa Meechinda (Panisa, 2009) with a topic of "Thai and Foreign Tourists' Loyalty toward Tourism Destination in Chiang Mai and Phuket Province" found that in Phuket, their motivation relates to novelty and status seeking while considering its scenery the most influential attribute. The Top 3 loyalty reasons of domestic drivers were (1) attachment with destination, (2) showing the place to others, and (3) exploring the destination, whereas those of international tourists were (1) satisfaction, (2) 
familiarity, and (3) attachment. Moreover, the research conducted by Nanthana Rophandung (Nanthana, 2005) investigating a topic of "Factor of Influence toward Tourist's Decision of traveling in Patong beach, Phuket province" found that the main travel purpose was that of relaxation. They decided to come to Patong Beach by themselves. The activities which they intended to do during vacation were sunbathing and water activities. Most of the tourists came with friends, stayed in hotels, and ate in restaurants. The important factor which influenced tourist's decision to travel to Patong Beach was the beautiful beach and its value for money. The most favorite of tourists in Patong was based on the purity and beauty of the beach. Most samples considered choosing an accommodation from their location and obtaining information from relatives and friends, with Phuket province advertising as the most important factor for a tourist's decision. Tourists were willing to travel to Patong Beach and would often want to return.

However, Patong Beach has developed continuously. It started with the sanitation district in 1986. Patong came into the local government era as decentralization of government policy. Patong was raised to be Patong municipal district in 1994. Later, Patong Beach has grown in economy and society. It was upgraded to a municipality in 2002. Presently, Patong has developed rapidly and continuously, especially tourism. Although Patong has high tourism potential as mentioned earlier, it has been questioned whether it was managed the sustainable tourism way. Sustainable tourism development is tourism that gives emphasis to the environment, both natural and man-made, and does not disturb or destroy social wisdom and culture, namely, languages, costume, food, or even livelihood. People can come to participate in tourism activities as much as they can, meanwhile, they can benefit from tourism by engaging in income-generating activities or running facilities in the community which have been developed primarily for tourism activities. Not only resources and local people will benefit from sustainable tourism development but also the private sector.

In terms of tourists, sustainable tourism development is an instrument to make them realize the importance of resources. Once they are satisfied with tourism, they might not destroy tourism resources because they will keep in mind that these resources belong to the people.

Nevertheless, the attempt for sustainable tourism development should be realized for the benefit of the next generation.

As mentioned earlier, this research aims to survey the existing tourism situation and the factors influencing sustainable tourism in Patong Beach. The research will create the updated database essential to develop the strategic plan and policy of sustainable tourism management in Patong Beach.

\section{Objectives}

1. To analyze the existing tourism situation of Patong Beach

2. To explore the factors influencing sustainable tourism in Patong Beach.

\section{Literature Review}

\subsection{Sustainable Tourism Development}

Sustainable tourism development is tourism which has to be environment-friendly, that is, both natural and man-made environment; does not disturb or destroy social wisdom and culture, namely, languages, costume, food, or even livelihood; must preserve the cultural, history, heritage, and arts of the local community (Edgell, 2006); and also people can come to participate in tourism activities as much as they can, at the same time gaining from tourism through incomegenerating projects or even running facilities in the community which are primarily developed for tourism activities. Not only resources and local people will benefit from sustainable tourism development but also the private sector. By achieving a particular combination of numbers and types of visitors, the cumulative effect of these activities at a given destination, together with the actions of servicing businesses, can continue into the foreseeable future without damaging the quality of the environment on which the activities are based (Middleton and Hawkins, 1998). In terms of tourists, sustainable tourism development is an instrument to make them realize the importance of resources. If they are satisfied with this kind of tourism, they might not destroy tourism resources because they will keep in mind that these resources belong to the people. Nevertheless, sustainable tourism development should be encouraged effectively, and should not be left for the next generations to solve.

\subsection{Community-based Tourism}

Community-based tourism or CBT is tourism that takes into account environmental, social, and cultural sustainability. It is 
managed and owned by the community, for the community, with the purpose of enabling visitors in order to increase their awareness and learn about the community and the local ways of life (REST, 1997). CBT consists of four key elements: natural and cultural resources, community organizations, management, and learning. For the host community to use tourism as a tool for community development, we mention 10 principles: (1) Recognize, support and promote community ownership of tourism; (2) Involve community members from the start in every aspect; (3) Promote community pride; (4) Improve the quality of life; (5) Ensure environmental sustainability; (6) Preserve the unique character and culture of the local area; (7) Foster cross-cultural learning; (8) Respect cultural differences and human dignity; (9) Distribute benefits fairly among community members; and (10) Contribute a fixed percentage of income to community projects. Before developing $\mathrm{CBT}$ in line with these principles, it is necessary to prepare and build the capacity of the host community to manage tourism. CBT marketing should also promote public awareness of the differences between CBT and mass tourism by educating people to realize the importance of CBT as a community tool for resource conservation and cultural preservation. This will attract appropriate tourists for CBT. Eventually, CBT is not the answer to "How does the community benefit from tourism?" But it is the answer to "How does tourism benefit community development?" (CBT-I, 2014).

\subsection{People Participation}

Participation is the result of an overall agreement in anything which members of the group want and the direction for changing is enough to generating a new project operation. The first reason of combination should be realizing an organization's operation in any activities. Therefore, an organization seems like a leader who takes charge of a group to achieve change) Yupaporn, 2002). The process of people participation involves joining the development, giving an idea, making a decision, and solving their own problem by themselves, especially through forceful participation of people to deal with a problem with suitable knowledge, while supporting and following the operation of concerned people and organization (Erwin, cited in Yupaporn Roop-Ngam, 2002, page 6) and achieving the community's goals. Because humans have the potential for change, the value of thinking and the capability of people are meaningless if participation and cooperation with each other are lacking (Rose, cited in Sanit Boonchoo, 1984, page 7).

\section{Methodology}

\subsection{Research Techniques}

\subsubsection{Documentary Analysis}

The documentary information investigated is obtained from many resources such as literature, the Internet, and other media for better understanding.

\subsubsection{Direct Observation}

To get preliminary data of the area of investigation, a researcher uses the following methods: survey, visit and photo taking of the study area to explore the related tourism activities such as the number and existing situation of tourist attractions, accessibility, facility, and security to both tourists and local people. Moreover, a researcher may observe as a participant and a non-participant in order to make a good opportunity for having interaction and familiarity with the local people in all tourism activities. With this regard, the researcher can stay close in order to explore the interaction and involvement between stakeholders, including any changes occurring in the research site.

\subsubsection{Questionnaire}

The questionnaire is designed to explore the perspective of local people in sustainable tourism development at Patong Beach in terms of tourism impact. The questions involve attitude of both Thai and foreign tourists toward tourism at Patong Beach consisting of topics, namely, tourist attractions, accessibility, facility, and security/safety.

\subsection{Analysis}

The qualitative data are periodically analyzed during the fieldwork, and interpreted according to the research objectives and theoretical framework. The tools of statistical frequency, percentage, the mean and standard deviation were used to translate the results using the SPSS program. 


\section{The Result of the Study}

\subsection{The Existing Tourism Situation of Patong Beach}

Regarding analysis of direct observation and questionnaire, we found that the existing tourism situation at Patong beach can be separated into two aspects. The first aspect is strength, which consists of four issues, namely, tourist attraction, accessibility, facility, and security. In terms of tourist attraction, we found that there are many places where tourists can travel and there are lots of activities they can do such as beach, diving, sun bath, massage, night life activity, and annual special events related with the attitude of local people. Thus, tourists can travel and engage in tourism activities all year round. In terms of accessibility to the place, the area has complete public transportation available (i.e., taxi, motorbike, and rental car). At the same time, the traffic system and traffic signs are supported by local people and tourists alike. In terms of tourism information accessibility, all respondents thought that there are many methods to get it such as a tourism handbook, the Internet, and a visitor center, as well as tourism staff. According to facility, there are several accommodations that can support tourists year-round. The standard is classified as an international standard level, which contributes trustworthiness to tourist. Moreover, public utility such as water supply, electricity, traffic system, and public health system can support tourism activity for the whole year as well. In terms of security/safety, there are 24-hour staffs attending to the safety of locals and tourists. Moreover, the CCTV cameras are installed around the area and prompt staffs are available all time. A disaster alarm system is also provided.

On the other hand, the second aspect of the existing tourism situation is weakness, which consists of four issues, namely, tourist attraction, accessibility, facility, and security. In terms of tourist attraction, tourism activity is hampered and the attractions are declining due to garbage accumulation in the area, waste water, landslide, and block out from high buildings, and so forth, which may greatly affect tourism. In terms of accessibility, traffic jams are occurring and the traffic signs are depreciating. At the same time, the tourism information accessibility lacks up date and staff is poor in English communication. According to facility, even if public transportation is available, some locals may take advantage of tourists, which may be a significant problem that will affect tourism at Patong Beach; also, public areas such as parking, toilet, and rest area are occupied by sellers and entrepreneurs, leaving tourists unimpressed. In case of security, tourism leads to several crimes to the place including drugs, prostitution, and problems on foreign workers and foreign entrepreneurs. These affected tourist reliance for travel to Patong Beach and may also affect the influx of potential tourists especially if they receive negative tourism information.

In conclusion, the existing tourism situation has its positive and negative aspects. These aspects lead to the search for a method that will manage sustainable tourism at Patong Beach. In terms of the positive aspect, if stakeholders realize the significance of it, they will participate to protect and preserve Patong beach in order to earn the trust of tourists. At the same time, in the case of the negative aspects, the stakeholders must not ignore but instead work on improvements, because a negative image may strongly impact a tourist's mind more than any positive observation. However, the existing tourism situation at Patong Beach is continuously being developed. It is time for all stakeholders to participate in managing the area through sustainable development. Finally, by moving together under one goal, Patong Beach may be a sustainable tourism destination in the future.

\subsection{Factors Influencing Sustainable Tourism at Patong Beach}

According to data analysis from the questionnaire distributed, both local people and tourists concerning background of respondents and attitude on the impact and local participation of tourism at Patong Beach as well as tourist's attitude on tourist attraction, accessibility, facility, and security/safety, found that many factors may influence sustainable tourism at Patong Beach. They should be sized and illustrated as follows.

Table 1: Description of the background of samples

\begin{tabular}{|c|c|c|c|c|c|}
\hline \multicolumn{2}{|c|}{} & NLPR $^{*}$ & PNLPR $^{\star \star}(\%)$ & NT $^{\star \star \star}$ & PNT $^{\star \star \star *}(\%)$ \\
\hline \multirow{3}{*}{ Sex } & Male & 35 & 29.20 & 46 & 38.30 \\
\cline { 2 - 6 } & Female & 85 & 70.80 & 74 & 61.70 \\
\hline \multirow{4}{*}{ Age (years) } & $\leqq 20$ & 3 & 2.50 & 3 & 2.5 \\
\cline { 2 - 6 } & $21-30$ & 49 & 40.80 & 80 & 66.70 \\
\cline { 2 - 6 } & $31-40$ & 54 & 45.00 & 28 & 23.30 \\
\cline { 2 - 6 } & $41-50$ & 14 & 11.70 & 9 & 7.50 \\
\cline { 2 - 6 } & $51-60$ & 0 & 0 & 0 & 0 \\
\hline
\end{tabular}




\begin{tabular}{|c|c|c|c|c|c|}
\hline & $\geq 61$ & 0 & 0 & 0 & 0 \\
\hline \multirow{4}{*}{ Education } & Primary School & 9 & 7.50 & 2 & 1.70 \\
\cline { 2 - 6 } & Junior High School & 17 & 14.20 & 4 & 3.30 \\
\cline { 2 - 6 } & Senior High School & 26 & 21.70 & 10 & 8.30 \\
\cline { 2 - 6 } & University & 65 & 54.20 & 104 & 86.70 \\
\hline \multirow{5}{*}{ Salary } & $\leqq 10,000$ & 17 & 14.20 & 1 & 0.80 \\
\cline { 2 - 6 } & $10,001-20,000$ & 63 & 52.50 & 46 & 38.30 \\
\cline { 2 - 6 } & $20,001-30,000$ & 26 & 21.70 & 34 & 28.30 \\
\cline { 2 - 6 } & $30,001-40,000$ & 11 & 9.20 & 28 & 23.30 \\
\cline { 2 - 6 } & $40,001-50,000$ & 3 & 2.50 & 8 & 6.70 \\
\cline { 2 - 6 } & $\geqq 50,001$ & 0 & 0 & 3 & 2.50 \\
\hline
\end{tabular}

*NLPR denotes number of local people respondents. **PNLPR denotes percentage of number of local people respondents.

***NTR denotes number of tourist respondents. *** PNTR denotes percentage of number of tourist respondents.

Table 2: Description of Attitude on Tourism Impact of Local People Respondents

\begin{tabular}{|l|c|c|}
\hline Issue & $\bar{x}$ & SD \\
\hline Positive Impact on Social & 3.38 & 0.99 \\
\hline Positive Impact on Environment & 2.80 & 1.04 \\
\hline Positive Impact on Economic & 3.84 & 0.91 \\
\hline Negative Impact on Social & 4.28 & 1.08 \\
\hline Negative Impact on Environment & 4.42 & 0.88 \\
\hline Negative Impact on Economic & 4.53 & 0.83 \\
\hline People Participation & 2.78 & 1.03 \\
\hline Total & $\mathbf{3 . 7 2}$ & $\mathbf{0 . 9 7}$ \\
\hline
\end{tabular}

Table 3: Description of Attitude on Tourism Supply of Tourist Respondents

\begin{tabular}{|l|c|c|}
\hline Issue & $\bar{x}$ & SD \\
\hline Tourist Attraction & 3.59 & 1.04 \\
\hline Accessibility & 3.14 & 1.00 \\
\hline Facility & 3.07 & 0.97 \\
\hline Security/Safety & 3.10 & 0.87 \\
\hline Total & $\mathbf{3 . 2 3}$ & $\mathbf{0 . 9 7}$ \\
\hline
\end{tabular}

Using Likert scale in analyzing the data of attitude of local people and tourists on tourism impact and supply, we found that the negative impact in any dimension is high, whereas the positive impact on environment and local participation are of moderate level, which is shown in Table 2. It means that tourism at Patong Beach has been inefficiently managed, affecting the local people. Moreover, tourists presented their opinion on tourism supply, and revealed that tourist attractions are of high potential to attract more visitors to the place but other supplies are of moderate level, as presented in Table 3. This means that the tourists are not impressed. Consequently, the high level of negative impact and the moderate level of unimpressed in tourism are factors influencing sustainable tourism at Patong Beach. Thus stakeholders should take action and manage tourism at Patong Beach in the way of sustainability.

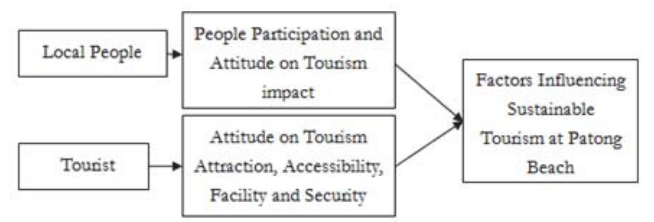

Fig. 1: Process of Getting Data of Factors Influencing Sustainable Tourism at Patong Beach

\section{Conclusions and Discussion}

The tourism at Patong Beach is continuously developed, especially in the dimension of positive impact, which includes environment, economic, and social value. As a result, the environment was developed in terms of increasing local people awareness in environmental conservation, having strict enforcement of environmental regulation, having cooperation 
between local people and governance for conserving and protecting environment, and having the effective development of environmental awareness. The economic community was developed in terms of local income distribution. Local people gained more income due to an increase in employment and community-goods selling. In terms of the social aspect, people can develop themselves by self learning on language, technology, and livelihood. These also brought about infrastructure development such as water supply, electricity, road, and public health, leading to community unity and increasing locally cultural awareness.

The progress of tourism at Patong Beach also generated many negative impacts. In terms of environmental impact, there have been increasing problems on garbage, sewage, dust, deforestation from construction, obscured views of buildings, trespassing into the public area affecting the land and sea eco-system, and reduction of sea creatures from fishing for tourism consumption. The negative economic impacts included a decrease of foreign tourists, a competency of local people to foreign workers, high cost of living, high cost of land and real estate, and local people's extravagance. Moreover, the negative impact in the social dimension was based on crime-related problems, such as prostitution, and sexually transmitted disease problems such as AIDS, venereal disease, drug problems, drug assembling, snatching, and thievery. More outside cultural imitation problems were about clothing and language; problems on child, lady, and elderly labor; and local shops taking advantage of tourists.

Not surprisingly, the factors influencing sustainable tourism at Patong Beach are generated from the existing tourism situation. These cover environment, social, and economic aspects. These have people, tourists, educators, governmental agencies, or even entrepreneurs who come to participate in managing tourism at Patong Beach in the way of sustainability. Finally, to earn the trust of tourist and local people, as well as other stakeholders, it is important to protect and preserve the place for the next generation.

\section{Recommendation}

This research is useful for people who are responsible for tourism management as it provides a database for finding the management strategy or for developing the current management strategy in the way of sustainability. In addition, local people and tourists, or even readers, know what the current tourism is, and how to change to sustainable tourism. The future research should explore the strategy of tourism development, along with stakeholder participation, for sustainable tourism development and community-based tourism.

\section{References}

Edgell, David L,(2006), Managing Sustainable Tourism: A Legacy for the Future.(pp:15.). New York: Haworth Press.

Jittima Kaewtae, (2005). Acceptance of news, Expectation and satisfaction of Thai tourists toward Patong beach, Phuket province. (pp:» Abstract).Thesis of Master of Arts (Communication), Dhurakij Pundit University, Bangkok.

Middleton, Victor T.C, and Hawkins, Rebecca, (1998), Sustainable Tourism: A Marketing Perspective. (pp: Preface), Massachusetts: ButterworthHeinemann.

Miller, Graham and Twining-Ward, Louise, (2005), Monitoring for a Sustainable Tourism Transition: The Challenge of Developing and Using Indicators. (pp: 38). Massachusetts: CABI Publishing.

Sanit Boonchoo, (1984). Community Development: People Participation. (pp: 7), Bangkok: Thammasat University Publishing.

Yapaporn Roop-Ngam, (2002), Participation on Bureaucratic Reform of the Bureau of the Budget. (pp: 5-6). Research Paper of Master of Arts (Social Development), National Institute of Development Administration, Bangkok.

ASTV, (2011), Bangkok-Phuket: Best destination of Asia-Pacific. [Online] Available: http://www.manager.co.th/Travel/ViewNews.aspx ?NewsID=9510000113415 (September 5, 2011)

ASTV, (2011), Tourism Authority of Thailand promoted Destination where got Kinnaree Award to tourists.[Online] Available: http://www.manager.co.th/Local/ViewNews.aspx?NewsID=9540000048960 (September 5, 2011)

Conde' Nest Traveler Magazine, (2010), Readers' Travel Awards 2009.[Online] Available: http://www.cntraveller.com/magazine/readers-travel-awards2009/countries (September 1, 2010)

Euromonitor International, (2012), Top City Destination Ranking 2009.[Online] Available: http://blog.euromonitor.com/2011/01/euromonitor-internationalstop-city-destinations-ranking.html (March 4, 2012)

Nanthana Rophandung, (2005), Factor of Influence toward Tourist's Decision of traveling in Patong beach, Phuket Province. [Online] Available: http://www.thaithesis.org/detail.php?id=1122548000076 (April 2, 2012)

Panisa Meechinda, (2009), Thai and Foreign Tourists' Loyalty toward Tourism Destination in Chiang Mai and Phuket Province. [Online] Available: http://research.trf.or.th/node/2283 (April 2, 2012)

Thaimuslimnews, (2011), Phuket got Best Asian Maritime Capital Award.[Online] Available: http://www.thaimuslim.com/view.php?c=6\&id=9653 September 5,2011

The Thailand Community Based Tourism Institute: CBT-I, (2014), Community Based Tourism. [Online] Available: http://www.cbti.org/2012/travel.php?\&lang=th (January 28, 2014)

Travel and Leisure Magazine, (2010), World's Best Award 2010: Top 5 Island in Asia. [Online] Available: http://www.travelandleisure.com/worldsbest /2010/cities (September 3, 2010) 